\title{
THE ACCREDITATION OF HUMAN RESOURCES AND PHYSICAL SPACE OF THE IRANIAN HEART CENTRE: COMPARISON TO THE NATIONAL AND INTERNATIONAL STANDARDS
}

\author{
Azar Jafaril, Masoumeh Bagheri-Nesami2, Mohammad Sadegh Rezai3, Fatemeh \\ Zamani', Amir Hossein Goudarzian' \\ 1. MSc Student of Nursing, Student research committee, Mazandaran University of Medical Sciences, Sari, Iran \\ 2. Department of Medical Surgical Nursing, Pediatric Infectious Diseases Research Center, Mazandaran University of Medical \\ Sciences, Sari, Iran \\ 3. Pediatric Infectious Diseases Research Center, Mazandaran University of Medical Sciences, Sari, Iran
}

Correspondence: drmsrezaii@yahoo.com

\begin{abstract}
OBJECTIVE:

Standardization of hospital resources and physical space can be an important strategy to increase productivity and effectiveness of services. The study was conducted with the aim of comparative accreditation of human resources and physical space in Mazandaran heart centre compared with the standards.
\end{abstract}

\section{METHOD:}

This comparative descriptive study was carried out in Sari city (centre of Mazandaran province) during 2016-2017. The data collection tool consists of two checklists for investigating the physical space and human resources of the hospital. To evaluate the quality of the content, a checklist was distributed to 5 experts from Mazandaran University of Medical Sciences. After corrections the checklist was applied. Data were analyzed by SPSS software version 16 and descriptive statistics.

\section{FINDINGS:}

The total number of nurses in this hospital was 288 and the total number of beds was 171. The human resources in the nursing, nutrition, operating room, anaesthesia departments were not standard. The ratio of total human resource to the number of beds was also estimated as 4.04. Results showed that the physical conditions in the hospital were moderately standard. The physical conditions of the hospital in most dimensions based on checklist, except the physical location of hospital and the features of its doors, were in accordance with the standard requirements.

\section{CONCLUSION:}

Considering the inappropriate distribution of human resource in the hospital and the non-standard design of physical space for providing services with better quality and increasing patients' satisfaction, it is recommended that experts control more carefully standard requirements.

\section{KEYWORDS}

hospital, physical condition, human resources, standards, Iran

\section{INTRODUCTION}

In most countries, hospitals are the most important medical institutions [1], such that among different components of health system, hospital services are the main factors in the growth of costs. [2] Human resources, as an important strategic factor, have also played a significant role in the productivity of health care organizations. [3] Based on the results of a study in 2009, $48 \%$ of the total hospital budgets were accounted for staffing costs. [4] This refers to the undeniable importance of hospital human resource and its significant role in hospital costs. [2] On the other hand, human resources employed in organizations should be 
regarded as a kind of capital, since the supply of human resources with specialized capabilities is not readily possible. [5] Therefore, shortcomings and surpluses of human resources have a significant effect on the quality of services to patients. [6, 7] The studies conducted by Shams [8] and Aazami [9] in Iran and Ritu [10] in India showed that there were insufficient human resources in related centres. However, the research of Davari [11] showed that the human resource of the anaesthesia department was desirable in Hazrat Rasool Hospital in Iran which had a different result with previous research. Bahrami Naraki [12] studied human resources of healthcare centres. They reported human resources more than standard requirements. Therefore, because of the importance of this matter and the different results had led us to examine the human resources available at the hospital.

The standard design and construction of physical space is another one of the important factor in improving the quality of care services. The standards vary in different societies based on socio-cultural, climatic, healthy conditions and social security. [13] When standards are well implemented in the design of health centres, good facilities will be provided for patients. [14, 15] Standards have a valuable role in demonstrating the least desirable and expected performance, targeting and determining the current state of the hospital, educational programs, evaluating, monitoring and directing the organization's activities. [16-18] The reports suggest that hospital standards of the ministry of health and treatment in Iran are not adequate and comprehensive due to inefficiency in presentation of weaknesses and shortcomings. [19, 20] Reviewing the researches that were done on the physical space of the hospitals $[19,13,18]$ showed that these studies evaluated only certain parts of the hospitals. To provide high quality services and increase the satisfaction of patients, the first step is to identify the strengths and weaknesses. This is possible by evaluating and comparing existing standards. [21]

Reviewing available databases showed that there were few articles published on the evaluation and standardization of healthcare centres, especially in Iran. Therefore, the present study was conducted with the aim of comparative accreditation of human resources and physical space in the Mazandaran heart centre in comparison with the standards in 2016-2017.

\section{METHODS}

This comparative descriptive study evaluated the human resources and physical space of Fatemeh Zahra Hospital affiliated with Mazandaran University of Medical Sciences (Sari, Iran) and compared them with the standards in 2016 2017. Fatemeh Zahra Hospital (Mazandaran heart centre) is a 171-bed educational hospital including CCU, ICU, Heart Surgery, CICU, Dialysis, Emergency, Post CCU, Angiography and Operating Room. The students in general medicine, cardiology and surgery residencies, internship, clinical pharmacology, nursing and paramedical students are being trained in this educational hospital.

\section{DATA COLLECTION TOOL}

The data collection tool was comprised of two researchermade checklists, a checklist for studying physical space of the hospital and a checklist for studying human resources of the hospital. Several sources [21-24] were used in the design of the checklist and the extraction of standards. The checklist was presented to 5 expert faculty members in Mazandaran University of Medical Sciences to evaluate the content validity. Checklist items in the dimension of human resources were assessment of nursing, physiotherapy (physiotherapist, physiotherapy technician and clerical staff), laboratory (laboratory specialist, laboratory expert, laboratory technician, and clerical staff); radiology (radiologist, radiology expert, radiology technician, clerical staff), technician of operating room, anaesthesia technician, nutritionist, finance, administrative affairs, services and pharmacy (pharmacist, pharmaceutical expert and technician of pharmaceutical affairs) relative to the number of beds in the hospital. Dimension of hospital physical space assessment also had 22 phrases: hospital location (5 phrases), land size

(1 phrase), doors' status (3 phrases), corridors' status (4 phrases), staircases' status (2 phrases), elevators' status (2 phrases) and bed size (5 phrases). Each of the items is measured to check the physical condition as follows: $0=$ non-standard (noncompliance with standards), $1=$ relatively standard (relative compliance with standards), 2 = completely standard (complete compliance with standards). Total scores vary from 0 to 44 . Scores are classified into 4 groups: (0-11), (12-22), (23-33), and (34-44). Therefore, the compliance of existing conditions with the standards is placed in poor, good, moderate and excellent levels based on obtained scores. 


\section{ETHICAL CONSIDERATIONS}

About 31 ethical codes that approved by research and technology assistance of Mazandaran University of Medical Sciences have been observed in present study [ethic code: IR.MAZUMS.REC.94.2043]. The data was collected after providing the necessary explanations about the research objectives and taking permission from the authorities of the research \& technology assistance of the university and the hospital. Also, the present study has attempted to avoid any prejudgment in the conclusions of the study by correct reflection of the information.

\section{DATA ANALYSIS}

Data was extracted from the checklist using SPSS software version 16 and descriptive statistics (frequency, mean, standard deviation, median, and mode).

\section{RESULTS}

Based on obtained results, the total number of nurses in this hospital was 288 and the total number of beds was 171 . Table 1 lists the available number of nurses and beds and their standard numbers in each department (table 1).

TABLE 1. THE NUMBER OF AVAILABLE NURSES AND BEDS IN DEPARTMENTS OF HEART HOSPITAL

\begin{tabular}{|c|c|c|c|}
\hline NAME OF WARD & $\begin{array}{l}\text { NUMBER OF } \\
\text { NURSES }\end{array}$ & $\begin{array}{l}\text { NUMBER OF } \\
\text { BEDS }\end{array}$ & $\begin{array}{l}\text { THE STANDARD NUMBER } \\
\text { OF NURSES RELATIVE TO } \\
\text { BEDS }\end{array}$ \\
\hline CCUI & 12 & 10 & 16 people per 5 beds \\
\hline CCU2 & 14 & 9 & 16 people per 5 beds \\
\hline CCU3 & 14 & 9 & 16 people per 5 beds \\
\hline CCU4 & 12 & 9 & 16 people per 5 beds \\
\hline CCU5 & 12 & 6 & 16 people per 5 beds \\
\hline CCU6 & 14 & 13 & 16 people per 5 beds \\
\hline CCU7 & 12 & 9 & 16 people per 5 beds \\
\hline CCU8 & 14 & 13 & 16 people per 5 beds \\
\hline ICUI & 25 & 8 & 16 people per 5 beds \\
\hline ICU2 & 22 & 9 & 16 people per 5 beds \\
\hline $\mathrm{CICU}$ & 17 & 8 & 16 people per 5 beds \\
\hline Post CCU & 16 & 20 & 16 people per 24 beds \\
\hline Heart A & 13 & 19 & 16 people per 24 beds \\
\hline Emergency & 28 & 14 & 32 people per 10 beds \\
\hline $\begin{array}{l}\text { Operating room for open } \\
\text { heart surgery }\end{array}$ & 15 & 3 & 38 people per 12 beds \\
\hline Dialysis & 22 & 10 & 38 people per 12 beds \\
\hline $\begin{array}{l}\text { Angiographic operating } \\
\text { room }\end{array}$ & 26 & 2 & 38 people per 12 beds \\
\hline Total & 288 & 171 & 420 \\
\hline
\end{tabular}


Also, based on results, the number of human resources employed in physiotherapy was 4, 12 in laboratory, 8 in radiology, 16 in technician of the operating room, 14 in anaesthesia technician, 1 in nutrition, 25 in financial affairs, 34 in administrative affairs, 95 in services and 8 in pharmacy. The statistics of the human resources employed at the hospital based on their employment type were as follows: formal staffs: 201, committed staffs: 97, conventional staffs: 155, staffs who have to work obligatorily for two years: 57 , non-formal nurse (corporate): 53, service staffs (corporate): 90, assignment staffs (typing \& printing, laundry, facilities, vehicles and kitchen): 38 and the total number of personnel is 691 people. The ratio of total human resource to the number of beds was also estimated as 4.04.
By comparing hospital location with existing standards, the hospital was not fully compliant with the standard requirements, but the hospital land size was completely compliant with standards. Details are given in Table 2.

The total score obtained in the physical assessment checklist showed that the physical conditions in the hospital were moderately compliant with standard. Based on the results, the physical condition of the hospital is relatively standard in most aspects except for the physical location and the characteristics of doors. Table 3 shows other details of physical condition of Fatemeh Zahra Hospital in Sari

\section{TABLE 2: HOLISTIC EVALUATION OF PHYSICAL SPACE OF HEART CENTRE}

\begin{tabular}{|l|l|l|}
\hline \multirow{5}{*}{$\begin{array}{l}\text { THE STUDIED } \\
\text { FEATURES }\end{array}$} & STATUS QUO & STANDARD \\
\hline \multirow{3}{*}{ Hospital location } & Relative compliance & Adequate space \\
\cline { 2 - 3 } & Relative compliance & Calm space \\
\cline { 2 - 3 } & Noncompliance & Surrounding areas \\
\cline { 2 - 3 } & Noncompliance & A location for helicopter \\
\cline { 2 - 3 } & Noncompliance & $\begin{array}{l}\text { Separate streets that are available for } \\
\text { doctors, patients and employees }\end{array}$ \\
\hline \multirow{2}{*}{ Land area } & Complete compliance $\left(780 \mathrm{~m}^{2}\right)$ & $42 \mathrm{~m}^{2}$ per bed \\
\hline
\end{tabular}

\section{DISCUSSION}

The present study compared the human resources and physical space of the Mazandaran Heart Centre educational hospital with the standards. The present results on standard compliance showed that the number of nurses relative to the number of beds in $\mathrm{CCU}, \mathrm{ICU}$, emergency and dialysis units was lower than the standard requirements. [22] Also, the standard number of human resources is estimated in following departments: laboratories: 12 people, physiotherapy: 3 people, radiology: 8 people, nutrition: 2 people, surgical technicians per active operating room: 10 persons, the technicians and expert anaesthesia personnel per active operating room: 11 people, pharmacy: 6 people [23], financial affairs: 25 people, administrative affairs: 34 people, and services: 26 people. [24] Based on present results, the number of human resources in laboratory, radiology and administrative affairs in Fatemeh Zahra Hospital was compliant with standard. On the other hand, human resources in the financial affairs, pharmacy, physiotherapy and services were higher than the standards, whereas the human resources in the nutrition, the operating room and anesthesia departments were lower than the standard. The results of a study on hospitals affiliated with Tehran University of Medical Sciences (University Type 1 in ranking) showed that the distribution of human resources was inappropriate in nursing, support and paramedical units. [3] Neyasi et al also stated that most of the hospitals' departments lacked human resources in different wards, especially nursing staff and para-clinical wards. [23] Researchers in another research with result analysis found that the hospital's emergency department faced shortages of nurses, especially in night shifts. [25] Matsumoto et al. noticed the inappropriate distribution of human resources in the health care sectors in Japan, the United States and the United Kingdom. [26] Also, according to research results in China, it was found that there was an inappropriate distribution of human resources, especially 
TABLE 3: DETAILS OF PHYSICAL CONDITION OF HEART CENTRE

\begin{tabular}{|c|c|c|c|}
\hline VARIABLE & STUDIED FEATURES & EXISTING DATA & STANDARD (24) \\
\hline \multirow{3}{*}{ Doors } & $\begin{array}{l}\text { Size of entrance doors of } \\
\text { vehicles }\end{array}$ & $3.5^{*} 2.5 \mathrm{~m}$ & $1.26-1.37 * 2.13 \mathrm{~m}$ \\
\hline & Size of corridor doors & $2.40 * 2.30 \mathrm{~m}$ & $2.40 * 2.40 \mathrm{~m}$ \\
\hline & Health doors of hospitals & Noncompliance & $\begin{array}{l}\text { Protected against fire and } \\
\text { infection }\end{array}$ \\
\hline \multirow{5}{*}{ Corridors } & Usual corridors & $2.25 \mathrm{~m}$ & $1.5 \mathrm{~m}$ wide \\
\hline & $\begin{array}{l}\text { Corridors of hospitalized } \\
\text { patients }\end{array}$ & $2.10 \mathrm{~m}$ & $1.26-2.13 \mathrm{~m}$ \\
\hline & Main corridor & $3.25 \mathrm{~m}$ & $3 \mathrm{~m}$ \\
\hline & Corridor of operating room & $3.10 \mathrm{~m}$ & 2.25 \\
\hline & Staircases & Relative compliance & Both sides should be railed \\
\hline \multirow{3}{*}{ Stairs } & \multirow{3}{*}{ Size of stairs } & Complete compliance & $\begin{array}{l}\text { Emergency stairs should not be } \\
\text { spiral }\end{array}$ \\
\hline & & $2 \mathrm{~m}$ & $\begin{array}{l}\text { The emergency staircases should } \\
\text { be } 1.50-2.50 \mathrm{~m} \text { wide }\end{array}$ \\
\hline & & $15 \mathrm{~cm}$ & $\begin{array}{l}\text { The height of stairs should be } 17 \\
\mathrm{~cm}\end{array}$ \\
\hline \multirow[t]{6}{*}{ Elevators } & Size of elevator & Relative compliance & $120 * 90 \mathrm{~cm}$ \\
\hline & \multirow{5}{*}{$\begin{array}{l}\text { The number and features of } \\
\text { elevators }\end{array}$} & Complete compliance & $\begin{array}{l}\text { An elevator for beds, patients, } \\
\text { visitors per } 100 \text { beds }\end{array}$ \\
\hline & & Relative compliance & $\begin{array}{l}\text { Two small elevators for } \\
\text { equipment and staff }\end{array}$ \\
\hline & & Relative compliance & $\begin{array}{l}\text { The elevators of wastes should } \\
\text { be separated }\end{array}$ \\
\hline & & Relative compliance & $\begin{array}{l}\text { The elevator should be big } \\
\text { enough for a bed and two } \\
\text { companions }\end{array}$ \\
\hline & & Complete compliance & Flat surfaces should be washable \\
\hline \multirow{5}{*}{ Bed size } & Bed length & $2 m$ & $2 \mathrm{~m}$ \\
\hline & Bed width & $95 \mathrm{~cm}$ & $90 \mathrm{~cm}$ \\
\hline & Bed height & $60 \mathrm{~cm}$ & $65 \mathrm{~cm}$ \\
\hline & The head of bed against wall & $0 \mathrm{~cm}$ & $10 \mathrm{~cm}$ \\
\hline & $\begin{array}{l}\text { The distance between the } \\
\text { end of two beds }\end{array}$ & $60 \mathrm{~cm}$ & $20 \mathrm{~cm}$ \\
\hline
\end{tabular}


nurses and doctors. [27] A study reported that the ratio of employed human resources to the active bed in all studied hospitals of Iran in 2015 was equal to 1.7, which corresponds to the health ministry's standard. [6] The total ratio of human resources to the number of beds in studied hospitals was higher than the standard requirements in the present study. But it seems that the distribution of human resources in some departments, especially nursing, has not been done fairly. The reasons for the different results of the studies are the different financial resources allocated for employing human resources, the amount of attention paid to human resources and the welfare and therapeutic conditions of patients in different regions.

The results of this study on compliance of physical status of Fatemeh Zahra hospital with standard requirements showed that the hospital had a relatively appropriate condition in terms of adequate and calm spaces and land area, whereas it did not comply the standards in terms of surrounding areas and lack of location for helicopter. In the design of the dimensions of the entrance doors of the vehicles and corridors, standard requirements were observed, but it should be noted that the hospital doors were not protected against fire and they did not have resistant surface coating against infection. The ordinary corridors, the main corridor, the corridor of the operating room, and the corridor of hospitalized patients were relatively standard. The staircases were also standard, although the height of stairs was lower than standard. The features and dimentions of elevators were nearly appropriate, so that the flat surfaces were washable, but their numbers were not proper. Results of the beds' size showed that the beds were relatively standard in terms of length, width, and height, whereas the position of the head of the bed against the wall as well as the distance between end of two beds were not standard. [28] Keyvanara et al studied the physical condition of hospitals and reported that Isfahan Hospital was in good condition in terms of the physical space of the paediatric ward. [13] Also, the results of a study showed that physical condition and the view and proportionality of public wards and emergency department were fairly acceptable in public and private hospitals. [14] Another study indicated that most of the emergency departments of the educational hospitals of Tehran University of Medical Sciences were in desirable condition in terms of space, activity and facilities. [1] In present study the emergency department of Fatemeh Zahra Hospital was also relatively standard in terms of space, facilities and physical conditions. Since climate conditions, location, constructional materials, and paying attention to health-treatment facilities play a significant role in the design of physical space and hospital structure, these factors may be possible reasons for different results of the studies.

\section{LIMITATIONS}

Ignoring the physical report of each of the hospital departments, due to the increase in the volume of the paper and the unavailability of an international standard instrument, are limitations of the present study that can be effective in generalizability of results. Another limitation of this research is the non-generalizability of the conclusion to all hospitals, in other words it can be used for comparison with the same type of hospitals with the hospital in our study. Therefore, further studies should be carried out on specialized hospitals in other regions of Iran, and the existing conditions of hospitals are compared with international standard instruments.

\section{CONCLUSION}

It seems that it is the first study published in the Middle East that examines the status of a heart centre hospital. According to results, the human resources in laboratory, radiology and administrative affairs were standard in heart centre hospital. Also, the number of human resources available in financial affairs, pharmacy, physiotherapy and services was higher than the standard; whereas human resources in nursing, nutrition, operating rooms, anaesthesia were lower than standard. Also, the results showed that the physical conditions in the hospital were moderately standard. Therefore, considering the importance of human resource management in hospitals and the physical conditions of health facilities for providing better quality services, it is recommended that the standards be monitored carefully by experts and the authorities. Also, the results of this study can be used for hospital and university officials to reach the standards level and increase the efficiency and quality of health care services.

\section{COMPETING INTERESTS}

The authors have no other relevant affiliations or financial involvement with any organization or entity with a financial interest in or financial conflict with the subject matter or materials discussed in the manuscript. This includes employment, consultancies, honoraria, stock ownership or options, expert testimony, grants or patents received or pending, or royalties. 


\section{ACKNOWLEDGEMENTS}

We would like to thank Mazandaran University of Medical Sciences, Sari-Iran, for its support and those participants in this study who carefully responded to our research questionnaire.

\section{References}

1. Rahmani H, Arab M, Akbari F, Zeraati H. Structure, process and performance of the emergency unit of teaching hospitals of Tehran University of Medical Sciences. Journal of School of Public Health and Institute of Public Health Research. 2006;4(4):13-22.

2. Abolhalaj $M$, Jafari-Sirizi $M$, Inalou $S$. A situational analysis of human resources in Iranian hospitals affiliated with ministry of health in 2008. Journal of Shahrekord University of Medical Sciences. 2010;12(1):60-8.

3. Ghazi Mirsaeid S, Mirzaie M, Haghshenas E, Dargahi H. Human Resources Distribution Among Tehran University Of Medical Sciences Hospitals. Payavard Salamat. 2013;7(5):432-46.

4. Hadian M, Mohammadzade A, Imani A, Golestani M. Analysis and Unit Cost Estimation of Services using "Step Down Method" in Fatemieh Hospital of Semnan University of Medical Sciences-2006; Iran. Journal of Health Administration. 2009;12(37):39-48.

5. Sadeghifar J, Pourreza A, Ahmadi B, Zeraati H, Arab M. Assessment of necessary staff for hospitals of llam university of medical sciences in accordance with personnel criteria and standards of Iranian health ministry. Journal of llam University of medical sciences. 201 1;19(1):24-31.

6. Adham D, Mahdavi A, Mehrtak M, Ebrahimi K, Azari A. Assessment of Human Resource Allocation in General University Hospitals in the Cities of East Azerbaijan Province. Journal of Health. 2015;6(5):507-16.

7. Kabene S, Orchard C, Howard J, Soriano M, Leduc R. The importance of human resources management in health care: a global context. Human Resources for Health. 2006;4(1):20.

8. Shams M. Investigation of situation of emergency ward in Iran medical science universities and compare with present standard. Tehran: Iran: Iran Medical Science University; 2001.

9. Aazami A. Investigation of situation of distribution occupied human capital in heath care centers of llam province. Tehran, Iran: Islamic Azad University, Research \& Science Branch; 1996.

10. Ritu N. Determining quality of public health care services in rural India. Clinical Governance. 201 1;16(1):35-49.
11. Davari A. Evaluation of Anastasia Ward about human capital and equipment in Iran medical sciences educational general hospitals and compare with Standard. Tehran: Iran: Iran Medical Science University; 2000.

12. Bahrami Naraki F. Investigation of Human capital in western Health centers of Iran medical sciences university and compare with present standard. Tehran: Iran: Iran Medical Science University; 1999.

13. Keyvanara M, Roholamin L. Comparison of Physical Space of Pediatric Wards in Isfahan Hospitals with Standards. Health Information Management. 2007;4(1):12332.

14. Seidi M, Akram Heidary A, Ashraf Khorramy-Rad A, Ahmary-Tehran H. Comparative Study of Patient Satisfaction, Physical Space and Medical Equipment between Governmental and Private Hospitals. Iran Journal of Nursing. 2009;22(59):42-50.

15. Zimring C, Joseph A, R. The Role of the Physical Environment in the Hospital of the 21st Century: A Once-ina-Lifetime Opportunity. healthdesign. 2004.

16. Cesarotti V, Di Silvio B. Quality management standards for facility services in the Italian health care sector. International Journal of Health Care Quality Assurance Incorporating Leadership in Health Services. 2006;19/67):451-62.

17. Sadeghi A, Azimzadeh N, Cheraghi F, Moghimbeigi A. Applying Structure and Process Standards of Medication Care at One of the Hamedan Hospital's Pediatric Wards in 1392. Scientific Journal of Hamadan Nursing \& Midwifery Faculty. 2014;22(1):70-9.

18. Sahebzadeh M, Hoseini M, Javadi Nejad N, Farazandeh M. The study of equipment, safety, hygine, personnel standards and their correlation with employee performance in surgery department of the educational hospitals in Isfahan 2009-2010. HOSPITAL 2011;10(2):76-87.

19. Ahmadi $M$, Khoshgam $M$, Mohamadpor A. Comparative study of the Ministry of Health standards for hospitals with Joint Commission International hospital accreditation standards. Hakim Research Journal. 2008;10(4):45-52.

20. Amerioun A, Tofighi S, Mahdavi S, Mamaghani $H$, Meskarpour Amiri M. Assessment of International Joint Commission (IJC) accreditation standard in a military hospital laboratory. J Mil Med. 201 1;13(2):75-80.

21. Aldana J, Piechulek H, Al-Sabir A. Client satisfaction and quality of health care in rural Bangladesh. Bulletin of the World Health Organization. 2001;76(6):512-7. 
22. Akbari Haghighi F, Kokabisaghi F, Yousefian S. Determining nursing manpower needed in a sample hospital. jhosp. $2011 ; 9(3): 69-76$.

23. Niazi S, Jahani M, Mahmoodi G. Evaluation of Human Resources in the Hospitals Affiliated to Babol University of Medical Sciences and Social Security of Qaemshahr City based on the Standards of the Iranian Ministry of Health. J Babol Univ Med Sci. 2016;18(2):56-63.

24. EghdamNia S. Mafahim va Standard hayeh Tashkilati. Tabriz: 2007.

25. NooriHekmat S, Dehnavieh R, Mohammadi N, Poorhosseini S, Rezai F, Mehralhasani M et al. Determining the Optimum Number of Nursing Staff Is Needed in Kerman Shafa Hospital Emergency Department. Tolooe Behdasht. 2014; 13(2):140-55.

26. Matsumoto M, Inove K, Farmer J, Inada H, Kajii E. Geographic distribution of primary care physicians in Japan Britain. Health Place. 2010;16(1):164-6.

27. Anand S, Fan V, Zhang J, Zhang L, Ke Y, Dong Z et al. China's human resources for health: quantity, quality, and distribution. The Lancet. 2008;372(9651):1774-81.

28. Neufert E, Neufert P. Architect's data. Omid Enghelab; 2012. 